\title{
Editorial
}

\section{On ethics and information}

It is with great pleasure that I present to you this issue of the journal. This is Vol. 40 as some of you might have noted. It is indeed a landmark in the life of our journal. To commemorate this I am starting a historical article series entitled ' 40 years ago'. Thanks to the help of Prof. Ramesh Chandra a lot of our archives have been retrieved and saved. It is from these that the current, very interesting article has been chosen representing IJPS Vol.1 No.1. It is about a rather large study of 750 clefts and reminds us that we still have not completed the massive documentation required for our cleft epidemiology. This current issue also carries another article about clefts. Last time we discussed a new approach as presented by Prof. Talmant from France. This time it is Prof. Michael Carstens from the US who writes about an embryology-based approach to the problem of clefting. The Editor is quite willing to have a debate in these pages about the various approaches via the 'Letters' pages.

For some time we have been debating ethics in clinical and experimental research. In this issue we publish an article which gives guidelines about ethics committees and their role as well as the links to more detailed information for those of you who are interested. In the future Ethics Committee clearance ought to be mandatory for any research work to be published. In today's world this is the minimum standard and your journal too will need to subscribe to these norms to stay current.

Finally, to a topic close to my heart for a very long time. We are all very active about ethics in research etc. but I do not really hear much about the same in the area of access to scientific research. Those who cannot afford expensive subscriptions are virtually denied access to several journals today. This is about IPR (Intellectual Property Rights) -of the publishers more than the authors. I would imagine most authors want as many peers as possible to read about their work, that is why they publish it in the first place. Fortunately, in medicine we do not enforce IPR in surgical innovations or else you would pay a fee every time you did someone's procedure. This is not true of journals. Access here is guarded jealously with fees to be paid for every paper you want to read as full text after say an online search. The argument being that unless someone paid, the whole edifice of publisher, search engine and so on was not feasible. The emergence of new strategies in the IT world, where advertising makes most applications free to the end user should give us an insight into new revenue models. If these end up allowing free access to knowledge albeit in exchange for seeing ads on the way, it will still be a huge boost to the thousands of doctors in developing countries who would otherwise never access that information. At the end of the day 'information is power' and we need to enhance free flow of information to colleagues around the world.

Our journal has from the beginning of our web venture remained 'Free Full Text'-against all odds. We therefore support the movement towards greater free access and hope this plea will be heard and acted upon.

\section{Mukund Thatte}

Editor, Indian Journal of Plastic Surgery, Mumbai, 167-F, Dr. Ambedkar Road, Dadar, Mumbai - 400 014, Maharashatra, India. E-mail: editor@ijps.org 